\title{
A Simulation Model for Predicting the Development of Cut Lily Based on Photo-Thermal Index
}

\author{
Yong-Yi Dong \\ Inner Mongolia University for the Nationalities, China \\ E-mail: dongyong74@126.com
}

\author{
Dong-Sheng An \\ Zhanjiang Experimental Station, Chinese Academy of \\ Tropcal Agricultural Sciences, China. \\ E-mail: dongshengan@126.com
}

\begin{abstract}
In order to provide accurate prediction of the development stages of cut lily, which is crucial for decision-making of the market schedule, a simulation model based on photo-thermal index (PTI) was developed to estimate the phenophase days during greenhouse production. Three experiments of Lilium Oriental Hybrids cv. 'Sorbonne' with different planting date were conducted in a PC multi-span greenhouse in Nanjing from March 2009 to January 2010 for data collection used in model construction and validation. The results showed the relative prediction error (rRMSE) between the observed days and the simulated days for each development stage were $1.58 \mathrm{~d}, 2.23 \mathrm{~d}, 2.54 \mathrm{~d}, 1.58 \mathrm{~d}$, respectively. The coefficient of determination $\left(r^{2}\right)$ between the predicted and the measured phenophase days were 0.97 with the error remained in 3 days, which is more accurate than growing degree day (GDD) based model. The model developed in this study gave satisfactory predictions of phenophase days, hence, can be used for florescence regulation in Sorbonne production.
\end{abstract}

Keywords-cut lily; development stages; model; phenophase days; photo-thermal index

\section{INTRODUCTION}

Lilium (liliaceae), one of five popular cut flowers in the world, is deemed as the king of flower bulbs. The produce area of Easter lily which occupies the most cultivated area increasingly extends in china due to its valuable and extensive use besides strong symbolic meaning. The price of lily depends on the scheduling to market and the post-harvest export time in transportation, which requires the accurate development simulation and robust florescence prediction to support the regulation of market scheduling.

The relationship between the temperature and the development of flower including the flower-bud size, weight and diameter from bud appearance to opening has been well known in many studies (Roberts et al. 1983; Halla et al. 2007). The study of six cultivars suggested no significant between flowering and light intensity, but to temperature (Persson \& Larsen 1998). The earlier prediction model concentrated on the development rate under the function of temperature in chrysanthemum (Hiden \& Larsen 1994) and cactus (Larsen et al. 1998). Taking account into the involvement of the effects of the light on flowering result from the fact that light intensity affects the photosynthesis and dry matter production which actually alter the time to flower (Genhua et al. 2001), daily light integral (DLI) was considered in modeling the chrysanthemum flower development (Persson \& Larsen
1999; Nothnagl 2004). The relationship between the photo-thermal ratio and the poinsettia quality has been confirmed (Liu \& Heins 1997). Considering the situation that the irradiance and temperature are not synchronized unlike the field, a new photo-thermal index was developed to solve this problem (Xu et al. 2010; Lu et al. 2011).

In order to provide concrete support to measure and control the marketing schedule, the research used Oriental Lily Sorbonne as experimental material, established a model of florescence prediction based on the new photo-thermal index with different planting dates.

\section{MATERIALS AND METHODS}

\section{A. Plant material and greenhouse environment}

The circumference of seed bulb Sorbonne, imported from Netherlands, was $14-16 \mathrm{~cm}$ and the plant density was 36 plants per square meter. The substrate of potting plant was 2:1:1 for sand, grass carbon and soil, respectively. The volumetric weight, $\mathrm{pH}$ and $\mathrm{EC}$ value were $1.08 \mathrm{~g} \cdot \mathrm{cm}-3,6.5$, and $0.76 \mathrm{mS} \cdot \mathrm{cm}-1$, respectively.

The experiments were taken in a PC multi-span greenhouse of Nanjing Agricultural Science Research Institute from March 2009 to January 2010. The green house was east-west trend with the length $28 \mathrm{~m}$ and two $8 \mathrm{~m}$ spans. The height of eaves and ridge was $3 \mathrm{~m}$ and $5 \mathrm{~m}$, respectively. The length, width and height of nursery bed were $25 \mathrm{~m}, 1.7 \mathrm{~m}, 1 \mathrm{~m}$, respectively. The heating pipes circled in the greenhouse ware used in winter. The wet curtain and fan cooling system was used in summer.

\section{B. Experiment design}

The planting date and collection period of three experiments were Mar 26, Apr 20, Sept 27 and Jun 15, July 4, Jan 21, respectively. The data of the first experiment were used to establish the model. The independent data required from the other two experiments were used to validate the model.

\section{Measurements}

The whole phenophase has been divided into four periods: planting stage (from planting to sprouting), seedling stage (from sprouting to basic three leaves unfolding completely), leaf-expansion stage (from the finished basic three leaves unfolding to the first visible bud), bud stage (from the first visible bud to the harvest). The days from the beginning to the end of each stage was recorded. 
The greenhouse environment data were automatically collected by CR1000 (Campbell Scientific Inc) with the frequency 1 minutes, average value including PAR (LI200X,Li-Cor Inc) above the canopy and air temperature at the height of $1.5 \mathrm{~m}$ above the nursery bed were recorded each 30 minutes.

The net photosynthesis Pn $(\mu \mathrm{mo} 1 \cdot \mathrm{CO} 2 \cdot \mathrm{m}-2 \cdot \mathrm{s}-1)$ of the leaves from the first to third under the first flower bud were measured and used to make light response curve (the CO2 concentration above the canopy was $380 \pm 20 \mu \mathrm{mol} \cdot \mathrm{mol}-1$, the measurement operated from 9:00 to 10:30). The maximum leaf net photosynthesis Pn,max $(\mu \mathrm{mol} \cdot \mathrm{CO} 2 \cdot \mathrm{m}-2 \cdot \mathrm{s}-1)$ was measured under saturate light intensity $(1500 \mu \mathrm{mol} \cdot \mathrm{m}-2 \cdot \mathrm{s}-1)$ with 3 repetitions in each stage.

The software SPASS v19.0 was used to statistical analysis and curve-fitting the data.

\section{Model description}

The irradiation and temperature effects were described as PARint(j) and TT(i,j), respectively. The photo-thermal index (PTI) was defined as relative thermal effect (RTE) multiplies the total PAR intercepted by the plant canopy (Xu et al. 2010). It can be given from equations (1) (3):

$$
\begin{gathered}
\operatorname{PTI}(j)=\left(\frac{1}{24} \sum_{i=1}^{24} T T(i, j)\right) \times P A R \text { int }(j) \\
P A R_{\text {int }}(j)=P A R(j) \times(1-\exp (-k \times L A I(j-1))) \\
T T_{T}=\frac{P_{n, \max }(T)}{P_{n, \max }\left(T_{0}\right)}
\end{gathered}
$$

Where PTI(j) is the accumulated PTI(MJ.pl-1) at the day $\mathrm{j}$, TT(i,j) is RTE at time $\mathrm{i}(\mathrm{i}=1-24 \mathrm{~h})$ in the day $\mathrm{j}$, PARint $(\mathrm{j})$ is

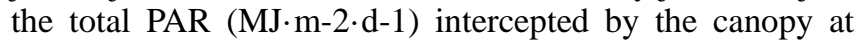

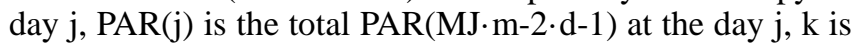
the extinction coefficient of the canopy (the value 0.702 is used in this study), LAI(j-1) is the LAI at day $\mathrm{j}-1$, TTT is the RTE at the temperature T, defined as the ratio of Pn,max at actual temperature (T) to optimal T (T0).

According to our environmental data collection (Fig. 1), the relationship between leaf net photosynthesis rate and environment temperature (Fig. 2) was described as equation (4):

$$
P_{n, \text { max }}(T)=\left\{\begin{array}{cc}
0 & T<T_{\text {min }} \\
P_{n, \text { max }}\left(T_{0}\right) \times \sin \left(\frac{\pi}{2} \times \frac{T-T_{\text {min }}}{T_{0}-T_{\text {min }}}\right) & T_{\text {min }} \leq T<T_{0} \\
P_{n, \text { max }}\left(T_{0}\right) \times \sin \left(\frac{\pi}{2} \times \frac{T_{\text {max }}-T}{T_{\text {max }}-T_{0}}\right) & T_{0} \leq T \leq T_{\text {max }} \\
0 & T>T_{\text {max }}
\end{array}\right.
$$

Where $\mathrm{T}$ is the temperature within the greenhouse, $\mathrm{Pn}, \max (\mathrm{T})$ is the $\mathrm{Pn}$,max at air temperature $\mathrm{T}$ and Tmax are the low limit, optimum and high limit temperature of lily growth with the values $5 \quad, 6,020^{\circ} \bullet \mathbf{C}$, respectively.

Then the accumulated PTI from day 1 to day m was defined as PTIsum(MJ·m-2) calculated by equation (5):

$$
P T I_{\text {sum }}=\sum_{j=1}^{m} P T I(j)
$$
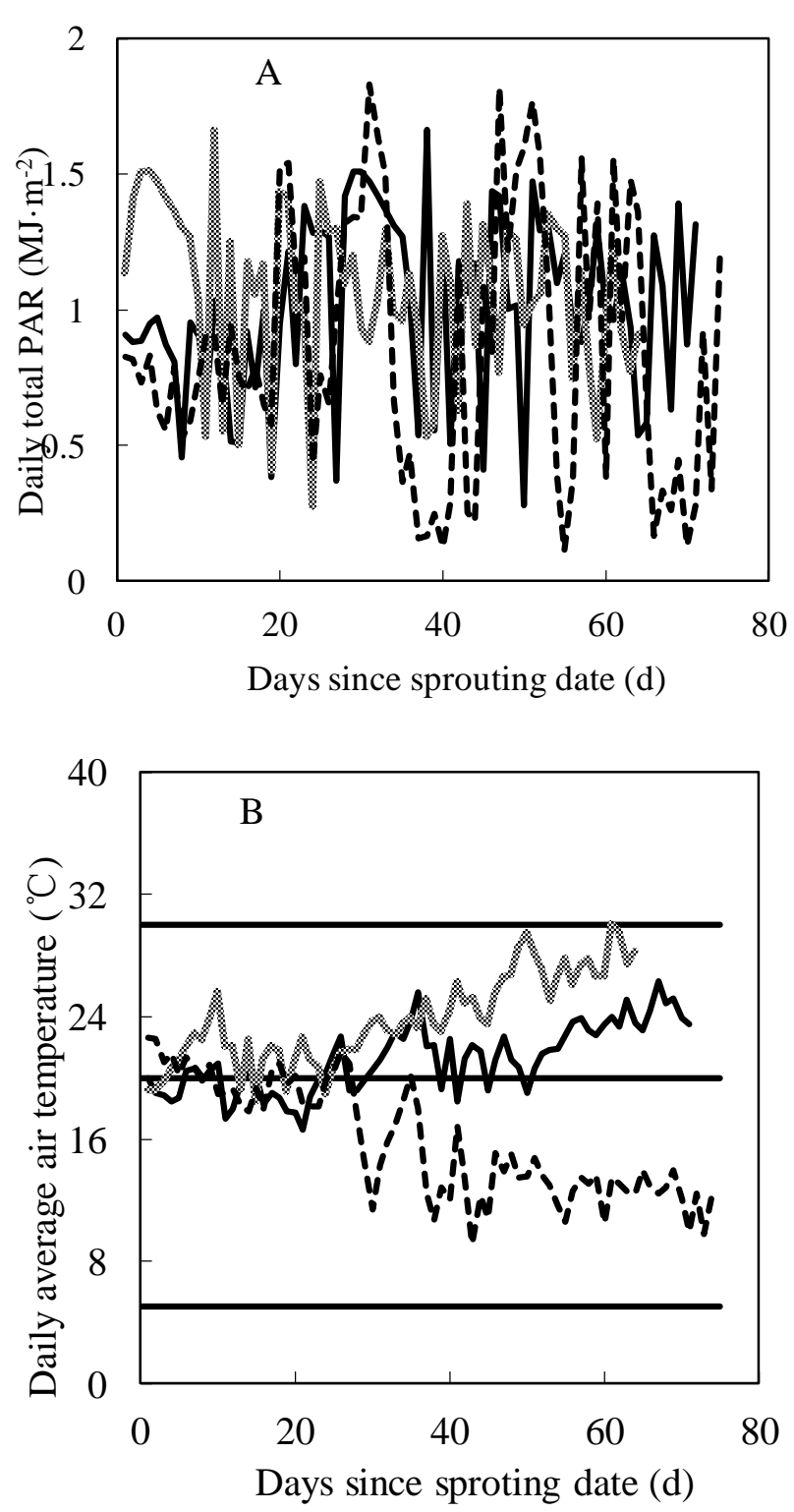

Figure 1 The daily total PAR (A) and daily average air temperature (B) inside the greenhouse since sprouting.

NOTE: Measured data for Exp.1, wæmeasured date for Exp.2,...Measured data for Exp. 3
${ }^{\circ} \mathrm{C} ; \mathrm{Tmin}, \mathrm{TC}$ 


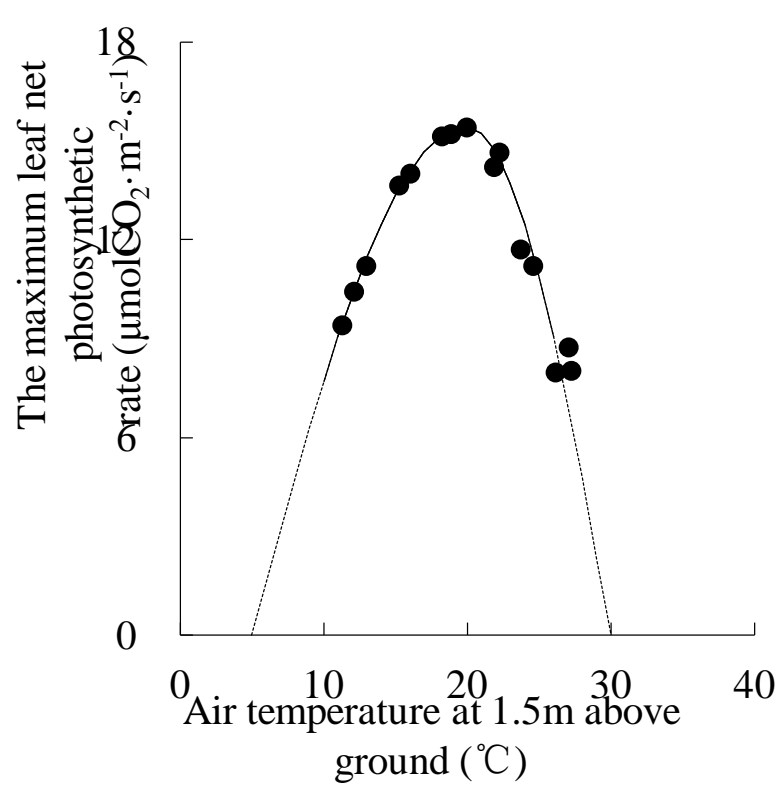

Figure 2 Relationship between maximum leaf net photosynthetic rate of Lilium 'Sorbonne'.

NOTE: (Pn,max) (values derived from the measured PAR response curve of Pn under saturated PAR conditions) and air temperature at $1.5 \mathrm{~m}$ above ground inside the greenhouse.

-Pn,max values derived from the measured PAR response curve of Pn Fitted curve

\section{E. Model validation}

The coefficient of determination (r2) and the relative root mean square error (rRMSE) between the predicted and measured values (from Exps 2-4) are used for model validation and calculated as:

$$
r^{2}=\frac{\left(\sum(x-\bar{x})(y-\bar{y})\right)^{2}}{\sum(x-\bar{x})^{2} \sum(y-\bar{y})^{2}}
$$

Where $\mathrm{x}$ is the measured data, $\mathrm{y}$ is the predicated data,

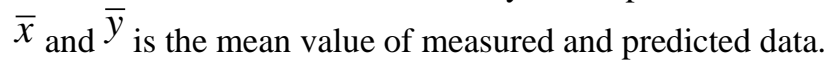

$$
r R M S E=\frac{1}{M} \sqrt{\frac{1}{n} \sum_{i=1}^{n}\left(\mathrm{OBS}_{i}-\mathrm{SIM}_{i}\right)^{2}}
$$

Where OBSi is the measured data, SIMi is the predicted data, $\mathrm{n}$ is the number of samples and $\mathrm{M}$ is the mean value of measured data.

\section{RESULT AND DISCUSSION}

By using the data from Exp I to calculate the PTIsum of cut Lilium at for each stage, the PTIsum of cut Lilium are $0.00 \mathrm{MJ} \cdot \mathrm{m}-2, \quad 0.02 \mathrm{MJ} \cdot \mathrm{m}-2,9.42 \mathrm{MJ} \cdot \mathrm{m}-2$ and 24.08 $\mathrm{MJ} \cdot \mathrm{m}-2$ for planting stage, seedling stage, leaf-expansion stage and bud stage, respectively.

The independent data used in model validation was adopted from Exp II and III. According to the accumulated PTI from Exp I and the photo-thermal data from Exp II and III, the calculated continuing days of each stage were used to estimate the starting and ending time. Comparing with the observed development time, the results showed an error in 3 days, which was more accurate than the GDD method we tested with the same data (Table. 1). The relative prediction error (rRMSE) between the observed days and the simulated days for each stage with PTI and GDD method were 1.58d, 2.23d, 2.54d, $1.58 \mathrm{~d}$ and $4.74 \mathrm{~d}, 3.54 \mathrm{~d}, 6.21 \mathrm{~d}, 5.38 \mathrm{~d}$, respectively. The coefficient of determination (r2) between the predicted and the measured phenophase days were 0.97 and 0.91 for PTI and GDD method (Fig. 3).

\begin{tabular}{|c|c|c|c|c|c|c|}
\hline phenophase & Item & Experiment II & Experiment III & PTI & (RMSE) & GDD (RMSE) \\
\hline & Observed & 8 & 14 & & & \\
\hline \multirow[t]{3}{*}{ Planting stage } & Simulated & 10 & 13 & & 1.58 & 4.74 \\
\hline & Error & -2 & 1 & & & \\
\hline & Observed & 6 & 13 & & & \\
\hline \multirow[t]{3}{*}{ Seedling stage } & Simulated & 7 & 16 & & 2.23 & 3.54 \\
\hline & Error & -1 & -3 & & & \\
\hline & Observed & 29 & 44 & & & \\
\hline \multirow[t]{3}{*}{ Leaf-expansion stage } & Simulated & 27 & 41 & & 2.54 & 6.21 \\
\hline & Error & 2 & 3 & & & \\
\hline & Observed & 28 & 45 & & & \\
\hline \multirow[t]{2}{*}{ Bud stage } & Simulated & 30 & 46 & & 1.58 & 5.38 \\
\hline & Error & -2 & -1 & & & \\
\hline
\end{tabular}

TABLE I. TABLE SIMULATED AND OBSERVED PHENOPHASE DAYS OF DIFFERENT VARIETIES OF CUT LILY (d) 


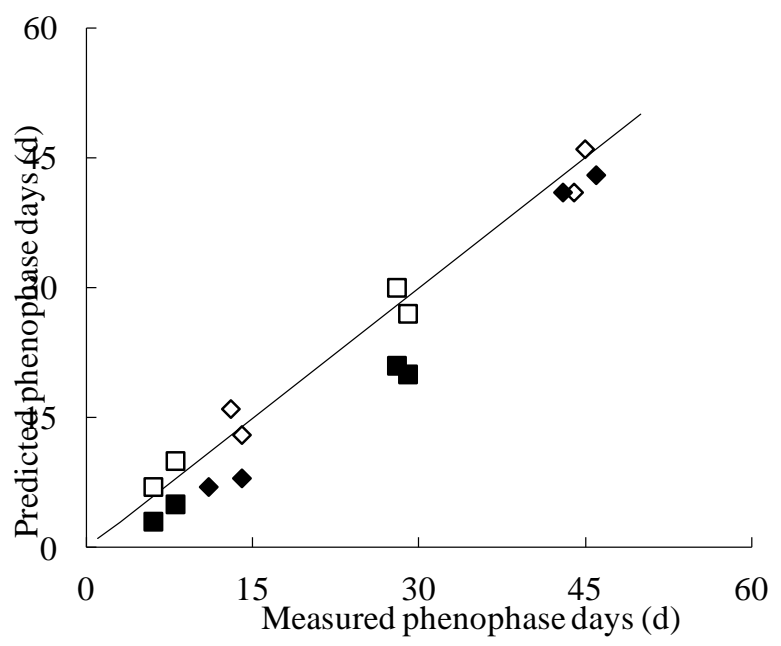

Figure 3 Comparison between predicted and measured phenophase days of different phenophase of cut lily.

NOTE: $\square$ Measured data for Exp. II $\diamond$ Measured data for Exp. III (PTI )

M easured data for Exp. II $\diamond$ M easured data for Exp. III (GDD)

$-1: 1$ line

GDD method has been comprehensively adopted in modeling the development rates of several field crop and plants, namely rice, maize, spruce, etc (Francois \& Boris 2009; Biing et al. 2009). The prediction of phenophase days of cut lily through GDD method showed a relatively bigger error due to the unsynchronized phenomenon between light and temperature caused by the artificial environmental control in the greenhouse. Meanwhile, considering the growth hysteresis induced by high temperature, the relationship between development rate and temperature in different range from the optimum to the upper or lower limit of temperature is not linear correlation (Yuan et al. 2005). Thus the single index of temperature and the assumption of the linear relationship between development rate and temperature are not sufficient to calculate the phenophase days for greenhouse crops.

Other than temperature, both photoperiod and light integral affect the initiation and development. According to the study on grandiflorum and cyclamen, high light integral promoted flowering and decreased time to flower (Nazrul et al. 2005; Wook et al. 2009). Science our lily material is not sensitive to photoperiod, the daily total PAR intercepted by the canopy was used to balance the effect of light integral on development rate. The relative photoperiodic effect (RPE) should be considered if the plant material is sensitive to photoperiod (Yuan et al. 2005). Whether the planting density or different places affect the development process need to be tested, further research should concentrate on the model modification under various water and fertilizer conditions.

\section{ACKNOWLEDGEMENT}

This research was funded by the Natural Science Foundation of China (NSFC) (31260483) and a project funded by the doctoral scientific research of Inner Mongolia University for the Nationalities (BS261). The authors thank the anonymous reviewers for their constructive comments.

\section{REFERENCES}

[1] Biing T. Guana, Chih-Hsin Chungb, Shu-Tzong Linc, Chieh-Wen Shend 2009. Quantifying height growth and monthly growing degree days relationship of plantation Taiwan spruce. Forest Ecology and Management Issue 11, 257, 2270-2276

[2] Francois Tardieu and Boris Parent 2009. Modelling temperature-compensated rates of development (an alternative to growing degree days) Comparative Biochemistry and Physiology Part A: Molecular \& Integrative Physiology Volume 153, Issue 2, S226

[3] Genhua Niu, Royal D. Heins*, Arthur C. Cameron, William H. Carlson 2001. Day and night temperatures, daily light integral, and $\mathrm{CO}_{2}$ enrichment affect growth and flower development of Campanula carpatica `Blue Clips'. Scientia Horticulturae 87, 93-105

[4] Halla, A.J., Catleya J.L., Waltonb E.F. 2007. The effect of forcing temperature on peony shoot and flower development. Scientia Horticulturae Volume 113, Issue 2, 188-195

[5] Hiden Cecilia, Larsen Rolf. U. 1994. Predicting flower development in greenhouse grown chrysanthemum. Scientia Horticulturae 58, 123-138

[6] Jadwiga Treder 2003. Effects of supplementary lighting on flowering, plant quality and nutrient requirements of lily 'Laura Lee' during winter forcing. Scientia Horticulturae Volume 98, Issue 1, 37-47

[7] Larsen R.U., Birgersson A., Nothnagl M., Karle Ân H. 1998. Modelling temperature and flower bud growth in November cactus (Schlumbergera truncata,Haw). Scientia Horticulturae 76, 193-203

[8] Larsen R.U., Persson L. 1999. Modelling flower development in greenhouse chrysanthemum cultivars in relation to temperature and response group. Scientia Horticulturae 80, 73-89

[9] Liu, B., Heins, R.D. 1997: Is plant quality related to the ratio of radiant energy to thermal energy? Acta Hort. 435, 171-182.

[10] Lu Lin, Wenwen Li, Jingqing Shao, Weihong Luo 2011. Modelling the effects of soil water potential on growth and quality of cut chrysanthemum (Chrysanthemum morifolium). Scientia Horticulturae 130, 275-288

[11] Nazrul Islam, Grete Grindal Patil, Hans Ragnar Gislerød 2005. Effect of photoperiod and light integral on flowering and growth of Eustoma grandiflorum (Raf.) Shinn. Scientia Horticulturae Volume 103, Issue 4, 441-451

[12] Roberts A.N., Yin-Tung Wang, Moeller F.W. 1983. Effects of pre- and post-bloom temperature regimes on development of Lilium longiflorum Thunb. Scientia Horticulturae Volume 18, Issue 4, 363-379

[13] Persson L. and Larsen R.U. 1998. Adapting a prediction model for flower development in chrysanthemum to new cultivars. Acta Hort. Int. Soc. Hortic. Sci, in press.

[14] Wook Oh, In Hye Cheon and Ki Sun Kim 2009. Photosynthetic Daily Light Integral Influences Flowering Time and Crop Characteristics of Cyclamen persicum. HortScience 44, 2341-344

[15] Xu, R., Dai, J., Luo, W., Yin, X., Li, Y., Tai, X., Han, L., Chen, Y., Lin, L., Li, G., Zou, C., Du, W., Diao, M. 2010. A photothermal model of leaf area index of greenhouse crops. Agric. Forest Meteorol. 150, 541-552.

[16] Yuan C M, Luo W H, Zhang S F, Dai J F, Jin L 2005. Simulation of the development of greenhouse muskmelon. Acta Horticulture Sinica. 32, 262-267. (in Chinese) 